\title{
MODELO DE NEGÓCIOS DO POLO DE INOVAÇÃO DO IFMG
}

\author{
Brenda Melissa Fonseca \\ Instituto Federal de Minas Gerais - Campus Formiga \\ brendafonseca4321@gmail.com
}

Érika Carolina Feijão

Instituto Federal de Minas Gerais - Campus Formiga carolinafeijao3472@gmail.com

\author{
André Bruno Silfer Monteiro \\ Instituto Federal de Minas Gerais - Campus Formiga \\ andresilfer97@gmail.com \\ Talita Bruna de Góes \\ Instituto Federal de Minas Gerais - Campus Formiga \\ talitadgoes@gmail.com
}

Luiz Guilherme Rodrigues Antunes ${ }^{1}$ Universidade de São Paulo luguiantunes@yahoo.com.br

\begin{abstract}
Resumo
Os polos de Inovação são considerados habitats de inovação, proporcionando a transferência de conhecimentos e tecnologias ao setor produtivo. No entanto, para que isso ocorra é necessário a gestão desse tipo de instituição, compreendendo, principalmente, a lógica do negócio desse tipo de entidade. Nesse sentido, o presente artigo objetiva analisar o Modelo de Negócios (MN) do Polo de Inovação do Instituto Federal de Minas Gerais (IFMG) localizado no Campus Formiga/MG. Para isso, utilizou-se da pesquisa qualitativa, exploratório-descritiva e com estratégia de estudo de caso. Assim, o estudo foi realizado no Polo de Inovação do IFMG, localizado no Campus de Formiga/MG, foram aplicadas três entrevistas semiestruturadas, por meio da adaptação do roteiro de Cavazza et al. (2018) e procedeu-se a análise de conteúdo temática. Como resultados encontrou-se três públicos-alvo compreendidos em industrial, governo e academia, em que cada um deles apresenta demandas específicas ao Polo. Tais demandas puderam ser convertidas na proposta de valor de transferência de tecnologia. Dessa forma, para que o valor ocorra, necessita-se das instituições parceiras como o IFMG e a EMBRAPII; de recursos físicos (infraestrutura), humana (gerencial), financeira, intelectual e social; e dos processos principais de desenvolvimento de projetos, capacitação de pessoal e vendas. Por fim, foi possível verificar que esse modelo de negócio se demonstra financeiramente deficitária, porém economicamente sustentável.
\end{abstract}

Palavras-chave: Modelo de Negócios. Polo de Inovação. IFMG.

\begin{abstract}
Innovation pole are considered innovation habitats, providing knowledge and technology transfer to the productive sector. However, for this to happen, it is necessary to manage this type of institution, especially understanding the business logic of this type of entity. In this sense, this article aims to analyze the Business Model (MN) of the Innovation Pole of the Federal Institute of Minas Gerais (IFMG) located at Campus Formiga / MG. For this, we used the qualitative approach, exploratory-descriptive research and strategy of case study. Thus, the study was conducted at the IFMG Innovation Pole, located at Campus de Formiga / MG, three semi-structured interviews were applied by adapting the script by Cavazza et al. (2018) and proceeded to thematic content analysis. As a result, we found three target audiences comprised of industrial, government and academia, each of which presents specific demands to the Pole. Such demands could be converted into the value proposition of technology transfer. Thus, for the value to occur, partner institutions such as IFMG and EMBRAPII are needed; physical (infrastructure), human (managerial), financial, intellectual and social resources; and the main processes of project development, personnel training and sales. Finally, it was possible to verify that this business model is financially deficient, but economically sustainable.
\end{abstract}

BUSINESS MODEL OF THE INNOVATION POLE OF IFMG

Keywords: Business Model. Innovation Pole. IFMG.

\footnotetext{
${ }^{1}$ Doutorando em Administração pela USP. Especialização em andamento em Pós-graduação em Docência pelo Instituto Federal de Minas Gerais. Mestrado em Administração pela Universidade Fderal de Lavras. Graduação em Adminsitração pela Universidade Federal de Lavras.
} 


\section{ARTIGO}

INOVAÇÃo

\section{INTRODUÇÃO}

A capacidade inovativa de uma nação está relacionada com ações de agentes institucionais em gerar e converter conhecimento em riquezas e desenvolvimento social (CAVAZZA et al., 2018). Assim, o conhecimento se torna um input fundamental ao processo inovativo, exigindo que as universidades e instituto federais se apresentem como principal lócus geradores de novos conhecimentos (SOUZA et al., 2019).

Como resultados da interação entre o setor acadêmico e o industrial têm-se a transmissão de tecnologias e conhecimento, articulados entre os campos da ciência, tecnologia e institucionalidades (MEYER-KRAMER; SCHMOCH, 1998; PAVITT, 1998), por meio dos chamados ambientes inovativos.

Esses ambientes inovativos, quando compreendidos pela abordagem dos Sistemas Nacionais de Inovação (SNI), compõe-se de múltiplos atores que contribuem para a geração, desenvolvimento e difusão de tecnologias advindas das pesquisas básicas e aplicadas (CAVAZZA et al., 2018). Assim, identifica-se tais atores como instituições que buscam fomentar o processo inovativo sob o rótulo de incubadoras de empresas, aceleradoras, parques tecnológicos, coworkings, instituições científicas e tecnológicas e polos tecnológicos e inovativos.

Nesse sentido, os polos tecnológicos e inovativos, foco do presente trabalho, apresentam intensa interação do tripé governo, instituição de ensino e pesquisa e setor produtivo, de modo que a necessidade das indústrias são combinadas com o conhecimento das instituições de ensino e pesquisa para a realização de inovações tecnológicas de elevado grau de novidade, financiadas e mantidas pelo governo (BARBIERI, 1994; SOUZA et al., 2019).

Sendo assim, compreendendo que os Polos, assim como os Parques Tecnológicos, são significantes e crescentes lócus de estudo, se faz importante analisar e discutir as especificidades desse tipo de instituição, analisando-o sobre a ótica de seu modelo de negócio (CAVAZZA, et al., 2018). Desse modo, o modelo de negócio pode ser entendido como uma ferramenta de gestão que cria valor a organização e aos seus parceiros, apresentando estratégias e táticas de como utilizar seus recursos para obter maior riqueza (OSTERWALDER, 2004; CASADESUS-MANSANELL; RICART, 2010; OSTERWALDER; PIGNEUR, 2011).

Sob essas ponderações, o objetivo desse artigo é analisar o modelo de negócios do Polo de Inovação do Instituto Federal de Minas Gerais (IFMG) localizado no Campus Formiga/MG. Dessa forma, justifica-se o presente estudo pelo mesmo contribuir para o campo de ambientes de inovação, lançando ênfase ao modelo de negócio como nível analítico (CAVAZZA, et al., 
2018; ANTUNES et al., 2019). Não menos que importante, ressalta-se que poucos estudos têm trabalhado os Polos Tecnológicos e Inovativos como entidades de análise, especialmente quando, segundo Torkomian (1994), esses podem ser compreendido como instituições diferentes dos Parques Tecnológicos.

Por fim, essa pesquisa encontra-se estruturada em mais quatro tópicos, além dessa introdução. Assim, no tópico seguinte apresenta-se o referencial teórico e, por conseguinte, os métodos e procedimentos. No terceiro tópico é apresentado o modelo de negócio do Polo de Inovação do IFMG. Por último, o quarto tópico expõe as considerações finais e referencias.

\section{INOVAÇÃO, AMBIENTES DE INOVAÇÃO E POLOS TECNOLÓGICOS E INOVATIVOS}

No ambiente organizacional, a palavra inovação tem sido utilizada de muitas formas, e geralmente está associada com a ideia de um objeto (CARVALHO; MACHADO, 2013), acarretando, portanto, no reducionismo do termo. Mais que isso, a inovação pode ser definida, inicialmente, como ideia, prática ou artefato concebido como novo, relevante e único, adotado em um determinado processo, área ou organização (ZALTMAN; DUNCAN; HOLBEK, 1973). Em uma abordagem macro, ela pode ser compreendida como mantenedora do desenvolvimento econômico para economias locais e capacidade competitiva das empresas em seu setor (FIORE; GRISORIO; PROTA, 2011; SANTOS; FAZION; MEROE, 2011) ou como força central no dinamismo do sistema capitalista (SCHUMPETER, 1982).

Para a literatura nacional e internacional a inovação tem-se apresentado sob várias tipologias, sendo as mais conhecidas as inovações de produto, processo, organizacional e de marketing (OECD, 2006); radical e incremental (SCHUMPETER, 1982); disruptiva (CHRISTENSEN, 1997); tecnológica (OECD, 2006); e técnicas e administrativas (DAMANPOUR, 1991). No entanto, independentemente da sua tipologia, são os ambientes de inovação que favorece o aparecimento dessas inovações, sustentam a competitividade e promovem o crescimento dos negócios.

Logo, esses ambientes "referem-se, portanto, ao conjunto de fatores políticos, econômicos, sociais e culturais que estimulam ou dificultam a inovação" (MACIEL, 1997, p.109). Tais espaços permitem a criação de tecnologias e conhecimentos ocasionados pela reconfiguração da organização em resposta ao conjunto de relações externas e internas que essas atmosferas podem proporcionar (MACEDO; DUARTE, 2013). 
Em nível governamental, a literatura também aborda os ambientes inovativos relacionados com Sistemas Nacionais de Inovação (SNIs). Os SNIs podem ser compreendidos como arranjos institucionais nos níveis nacionais, regionais ou subnacionais (FREEMAN; SOETE, 2008), que combinam a visão sistêmica e abrangente da inovação com as especificidades sociais, de modo que haja crescimento e exploração das economias locais (FIORE; GRIOSORIO; PROTA, 2011; TRIPPL, 2010; ALMEIDA; FIGUEIREDO; RUI SILVA, 2011).

No contexto brasileiro, o SNI é fortalecido pelo arcabouço institucional, que podem ser traduzidos na Lei Federal de Inovação (10.793/2004), atualizada pela Lei 13.243/2016 e Decreto $n^{\circ}$ 9.283/2018; Lei Federal de Propriedade Industrial (9.279/1996); e Fundos Setoriais de Fomento à Pesquisa, Desenvolvimento e Inovação (CAVAZZA et al., 2018). Como grande contribuição destaca-se o favorecimento das atmosferas de inovação pela União, Estados, Distrito Federal e Municípios e Instituições de Ciência e Tecnologia (ICTs) na "criação, implementação e consolidação de ambientes promotores da inovação, incluindo os parques e polos tecnológicos, como forma de incentivar o desenvolvimento tecnológico, aumento da competitividade e interação entre as empresas e as ICTs" (BRASIL, 2016) por meio de subsídios financeiros, humanos, materiais ou de infraestrutura.

Assim, encontram-se dentro do SNI instituições que visam fomentar o desenvolvimento tecnológico e inovativo, por meio da relação governo-academia-empresa. Essas instituições apresentam-se sob o rótulo de incubadoras de empresas, parques tecnológicos, aceleradoras e o Polos Tecnológicos e Inovativos, sendo esse último o foco da pesquisa. Os Polos Tecnológicos, portanto, se caracterizam pela presença de pequenos e médias empresas de determinada área em um espaço geográfico, com potencial tecnológico intenso, com vínculos com universidades e institutos de pesquisa que tenham como objetivo a execução de pesquisa básica ou aplicada de caráter científico ou tecnológico (MCTIC, 2019).

Os Polos emergiram nos Estados Unidos, com as experiências do Vale do Silício (Califórnia) e da Route 128, e apresentam em comum o agrupamento de empresas de base tecnológica cuja criação está associada com as instituições acadêmicas de alto padrão, localizados nas suas imediações. Nesse sentido, Medeiros et al. (1992) argumentam que os polos tecnológicos apresentam quatro elementos estruturantes, que são: (i) instituições de ensino e pesquisa, que se especializam em novas tecnologias; (ii) aglomerado de empresas; (iii) projetos conjuntos de inovação tecnológica na relação universidade-empresas-governo; e (iv) estrutura organizacional apropriada. 
Logo, observa-se, nesses elementos, a ênfase no papel da territorialidade, não somente pela questão econômica, mas como um arranjo produtivo focado no desenvolvimento social, por meio das potencialidades das universidades e institutos de pesquisa, ocasionando novas tecnologias e inovações ao setor industrial (MARIGHETTI; SPOSITO, 2009). Como objetivos, os Polos buscam: (i) promover a criação e consolidação de empresas de base tecnológica; (ii) fornecer apoio gerencial por meio de consultorias e capacitações nas áreas de gestão tecnológica e empresarial aos negócio e ao setor acadêmico; (iii) mediar e facilitar as interações entre as empresas e a academia, possibilitando que haja utilização de recursos humanos, equipamentos e laboratórios de forma compartilhada; e (iv) fomentar a participação de instituições financeiras e governamentais (MEDEIROS; MATTEDI; MARCHI, 1990; TORKOMIAN, 1994).

Segundo Medeiros, Mattedi e Marchi (1990) os polos podem ser separados em três tipologias, em que polos do Tipo 1 não apresentam estrutura organizacional formal e a organização dos projetos é realizada pelos envolvidos no planejamento conjunto (governo, empresa e academia). Já os polos do Tipo 2 possuem estrutura organizacional formal desenvolvida por instituição particular sem fins lucrativos e seus objetivos são a coordenação das parcerias visando criam pesquisas e tecnologias. Por último, o polo do Tipo 3, também conhecidos como parques tecnológicos, também possuem estrutura organizacional formal, porém legal, com infraestrutura física próxima as instituições de ensino e pesquisa e abrigam empresas de alta tecnologia. Nessa tipologia, os projetos contam com o compartilhamento de infraestrutura das universidades as indústrias. No entanto, cabe ressaltar que no Brasil, segundo Martins e Wander (2018), os polos tecnológicos e inovativos não se diferenciam, em princípio, dos de outros países, mas o que as tornam singulares são as trajetórias e experiencias que ditam as suas velocidades de desenvolvimento.

\section{MODELO DE NEGÓCIO DE AMBIENTES DE INOVAÇÃO}

Os estudos sobre modelos de negócio são considerados recentes, principalmente pelo estudo de Osterwalder (2004), e tem ganhado maior notoriedade devido ao surgimento das tecnologias, globalização, hipercompetição e rearranjo dos negócios (ANTUNES et al., 2019).

Dessa forma, o modelo de negócio surge como uma ferramenta de gestão que se localiza entre as estratégias e táticas organizacionais de modo que na camada estratégica se encontra o nível de planejamento empresarial, referindo-se a escolha mais competitiva do modelo de negócio a ser aplicado na empresa, enquanto na camada tática se localizam as arquiteturas, 
INOVAÇÃO

lógicas e fluxos de trabalho associadas com a aplicação do modelo de negócio na organização (OSTERWALDER, 2004; CASADESUS-MASANELL; RICART, 2010).

Assim, ao se considerar a proliferação de estudos sobre esse instrumento, uma variedade enorme de estudos tem sido publicada, apresentando, principalmente, definições e elementos de modelo de negócio. No entanto, por maior que sejam as contribuições teóricas em termos de definições e elementos, Antunes et al. (2019) apontam que os modelos de negócio mais tradicionais não podem ser aplicados ao contexto dos ambientes de inovação, visto que esses moldes são limitadores por não possibilitar a compreensão completa da lógica das instituições inovativas. Assim, na tentativa de propor um modelo específico para incubadoras de empresas e parques tecnológicos, Cavazza et al. (2018) e Antunes et al. (2019) propuseram uma definição mais propícia a essas atmosferas. Logo, na visão dos autores, o modelo de negócio pode ser compreendido como a lógica que evidencia a criação e entrega de valor aos clientes/públicos e sua suposta geração de receitas lucrativas e sustentáveis, utilizando-se de processos-chave, alocação de recursos e do estabelecimento de relacionamentos com os stakeholders. O Quadro 01 apresenta os componentes dessa definição.

Quadro 01 - Componentes do modelo de negócio da incubadora de empresa

\begin{tabular}{cl}
\hline $\begin{array}{c}\text { Componentes do Modelo de } \\
\text { Negócio }\end{array}$ & \multicolumn{1}{c}{ Descrição dos Componentes } \\
\hline Valor & Reflete o conjunto de produtos e serviços que os clientes estão dispostos a pagar. \\
Segmento de Clientes & Refere-se ao público alvo que o negócio busca oferecer o valor. \\
Receitas & Forma que a organização obtém receitas. \\
Processos-chave & Conjunto de processos que agregam valor ao pacote de produtos e serviços. \\
Recursos & Recursos tangíveis (físicos, humanos e financeiros) e intangíveis (intelectuais e \\
& sociais) associados aos processos-chave. \\
Stakeholders & Conjunto de gentes envolvidos com o negócio da instituição, como agentes \\
& governamentais, fornecedores, clientes e demais. \\
\hline
\end{tabular}

Fonte: Cavazza et al. (2018) e Antunes et al. (2019).

Nesse sentido, cabe enfatizar que para essa pesquisa utiliza-se da conceituação e componentes apresentados pelos autores, uma vez que esses elementos se adequam melhor ao negócio do Polo Tecnológico e por já terem sido aplicado a outros ambientes de inovação como Parques Tecnológicos e Incubadoras de Empresas. 


\section{MÉTODOS E PROCEDIMENTOS}

Essa pesquisa é desenvolvida segundo a abordagem qualitativa, visto que visa relacionar um objeto de estudo com a realidade, conforme diversas lentes interpretativas do investigador (RAMOS; RAMOS; BUSNELLO, 2005). Além disso, conforme os objetivos, se caracteriza como exploratório-descritivo, sendo que a pesquisa exploratória é utilizada quando não se há um conhecimento prévio sobre o fenômeno (GODOY, 2005; GIL, 2008) e a pesquisa descritiva intenciona a descrição e análise buscando investigar as relações de um fenômeno (RICHARDSON, 1989).

Como estratégia de pesquisa optou-se pelo estudo de caso, ou seja, investiga-se o Polo de Inovação de Inovação do Instituto Federal de Minas Gerais (IFMG). Atualmente o Polo está localizado no Campus de Formiga (MG) e foi criado em 2014, pela parceria do IFMG com um grande grupo do setor automobilístico, por meio da chamada pública 02/2014 da Empresa Brasileira de Pesquisa e Inovação Industrial (EMBRAPII). Como estrutura organizacional, essa instituição compõe-se de diretoria geral, coordenadoria de prospecção de projetos, coordenação de portfólio (onde tem-se também a gestão de projetos) e a coordenação de pessoas, administrativa e financeira. Além disso, também conta com o suporte do IFMG e da Fundação Arthur Bernardes (FUNARBE). Por último, destaca-se que essa instituição apresenta estreita ligação com docentes e pesquisadores, sendo esta equipe composta por cientistas da computação, engenheiros, físicos, administradores, publicitário, jornalistas, dentre outras qualificações (POLO DE INOVAÇÃO DO IFMG, 2016).

Para a coleta de dados, utilizou-se de entrevistas semiestruturadas, em que se adaptou o roteiro de Cavazza et al. (2018). Dessa forma, o roteiro apresenta dois blocos, em que o primeiro deles visou a caracterização do respondente, e o segundo abarcou o modelo de negócio. Como sujeitos da pesquisa entrevistou-se quatro representantes diretamente ligados ao objeto de estudo. O Quadro 02 os caracterizam.

Quadro 02 - Caracterização dos entrevistados

\begin{tabular}{ccc}
\hline Entrevistados & Cargo no Polo & Tempo de Serviço \\
\hline E1 & Coordenador Geral & 16 meses \\
E2 & Colaborador & 18 meses \\
E3 & Coordenador de Prospecção de Projetos & 7 meses \\
\hline
\end{tabular}

Fonte: Elaborado pelos autores. 
Para a seleção dos entrevistados estabeleceu-se os seguintes critérios: (a) representatividade, ou seja, deveriam fazer parte do corpo de colaboradores do Polo de Inovação; (b) disponibilidade, isto é, aptos a participarem da pesquisa; e (c) ter ao menos seis meses de exercício na Instituição. Justifica-se a aplicação desse último critério por compreender que um participante do polo, com pelo menos seis meses de exercício, teria condições de responder as indagações da coleta de dados.

Para a operacionalização das entrevistas, inicialmente, os pesquisadores explicitaram os objetivos do estudo, bem como esclareceram as eventuais dúvidas. Solicitaram, também, a gravação dos depoimentos. Assim, as investigações tiveram, em média, 30 minutos de duração, os quais foram, posteriormente, transcritos na íntegra.

Logo após, realizou-se as análises de conteúdo, que segundo Bardin (2016) é um conjunto de técnicas de apreciação das comunicações que busca obter, sistematicamente, a descrição dos conteúdos das mensagens, permitindo a inferência de conhecimentos relativos às condições de produção/recepção dessas mensagens. Logo, procedeu-se três etapas: pré-análise, exploração do material e tratamento dos resultados obtidos e interpretação.

$\mathrm{Na}$ primeira etapa realizou-se a preparação e organização do material, leitura e codificação. Posteriormente, na etapa de exploração e tratamento foram localizados os trechos das narrativas mais pertinentes, conforme a grade fechada estipulada previamente. Assim, a construção da grade embasou-se nas categorias do modelo de negócio, isto é, valor, segmento de clientes, receitas, processos-chave, recursos e stakeholders. Por último, foram analisados os trechos selecionados conforme a literatura de modelos de negócio e de polos. Na sequência apresentam-se os resultados e discussões.

\section{RESULTADOS E DISCUSSÃO}

\subsection{ANÁliSE DOS COMPONENTES DO MODELO DE NEGÓCIO DO POLO DE INOVAÇÃO DO IFMG}

Como primeira categoria, ou elemento do modelo de negócio, tem-se o segmento de clientes, que são os clientes-alvo que a organização quer oferecer valor (OSTERWALDER, 2004). Segundo Hijjar (2000) a segmentação tem por objetivo identificar grupos com características e expectativas semelhantes nos quais buscam servir e criar valor. Segue, portanto, trechos ilustrativos dos relatos dos entrevistados sobre essa categoria: 
“(...) Então, os públicos alvos são os empresários né (...) são vários públicos que são beneficiados né, os acadêmicos e o público externo que são os empresários e a sociedade também” [E2].

"Na minha opinião a gente tem dois segmentos de clientes que a gente pode analisar: o que é óbvio né são as indústrias (...) Eu só consigo atender esse segmento de clientes [industrias] se eu tenho pesquisadores dispostos para trabalhar no Polo (...) a gente deveria contemplar esses dois segmentos de clientes" [E3].

“(...) Nós não somos uma coisa isolada do IFMG, somos uma instância do IFMG. É do IFMG e não é nem do Campus Formiga. (...) A EMBRAPII é o parceiro no desenvolvimento do negócio do Polo" [E3].

Conforme os fragmentos extraídos, compreende-se que o Polo apresenta três grandes públicos diretos, que são: a indústria, por meio da sociedade empresarial; os pesquisadores e o IFMG, como comunidade acadêmica; e a EMBRAPII, como organismo público. Não menos que importante, cabe destacar a sociedade civil que se beneficia, indiretamente, com as atividades do Polo. Além disso, as entrevistas evidenciaram as necessidades dos públicos-alvo. Logo, o setor industrial busca a Instituição visando a capacitação técnica, resolução de problemas e inovação tecnológica. Já na comunidade acadêmica, a sua necessidade está envolvida com a possibilidade de se colocar em prática os conhecimentos criados e difundidos dentro dos espaços acadêmicos. E, por último, o setor público tem como necessidade o desenvolvimento inovativo local e nacional, por meio do fomento as práticas inovadoras.

A segunda categoria, valor, está associado com a criação e entrega de valor. Assim a criação relaciona-se com a perspectiva do processo produtivo de criação do pacote de produtos e serviços (BOWMAN; AMBROSINI, 2000), enquanto a entrega se refere a oferta desse pacote, bem como com a percepção do cliente acerca desse valor. Portanto, obteve-se os seguintes relatos:

“ (...) As empresas buscam apoio e desenvolvimento de seus projetos de inovação, e esse público aqui eu estou entendendo como cliente (...) [mas] o modelo de negócio falhou, ainda temos que reconhecer que se deve desenvolver estratégias para esse público que é o pesquisador, sem ele a gente não pode atuar aqui, (...) a gente deveria assumir eles como clientes, como uma forma de captá-los para o Polo (...)” [E3]

“(...) nesse ano nós vamos chegar em um bilhão em contratos assinados, eu acho, eu vejo o seguinte, é onde a transferência de tecnologia do setor público das universidades, das instituições de ensino de pesquisa para as empresas ela está acontecendo de fato (...) os professores têm tempo para entregar um projeto, os alunos estão envolvidos com desafios reais 
da empresa, aquele produto que foi desenvolvido dentro do Polo ele vai ser usado na empresa (...)” [E1]

Conforme os trechos apontados, percebe-se que o pacote de produtos e serviços desenvolvido pelo Polo está associado com a transferência de tecnologia. Esse aspecto é observado quando considerados os três grandes públicos do Polo. Em outras palavras, a transferência de tecnológica se transforma em valor à medida que: (i) o Polo de Inovação consegue atender as demandas das empresas por meio de prestação de serviços de alta qualidade, traduzidos no desenvolvimento de projeto (Público Empresarial); (ii) o governo consegue estabelecer, por meio do financiamento e legalização, condições para que a tecnologia seja transportada da academia para o processo produtivo industrial (Público Governamental); e (iii) a parceria com os pesquisadores e discentes proporcionam a elaboração dos projetos de tecnologia, por meio da relação teoria e prática (Público Acadêmico).

A terceira categoria são as receitas. Segundo Timmers (1998) e Osterwalder (2004), elas descrevem como uma organização ganha dinheiro, seja por base em taxas de adesão, vendas de produtos, serviços, porcentagem sobre transação e outras formas. Assim, obteve-se:

“(...) a gente depende de recursos da reitora que ajuda a gente pagar passagens, diárias, pagar o material do expediente, às vezes precisa comprar... então a gente precisa de recursos da reitoria, que nos auxilia nestas questões básicas (...)” [E2].

"O Polo não recebe financiamento da EMBRAPII. Quem recebe financiamento da EMBRAPII são as empresas que têm esses projetos aprovados (...)” [E3].

“(...) vamos entender como funciona essa questão no Polo. A gente tem uma equipe fixa (...) somos todos vinculados ao IFMG (...) o Polo não tem que custear isso (...) [nós] não [temos] lucro nos projetos, a gente não ganha dinheiro nos projetos (...). O que se faz, a empresa chega aqui com uma demanda, vamos supor que a gente faz uma proposta técnica e identifica que essa proposta, esse projeto como um todo custa 300 mil reais, certo. Aí a gente envia esse bolo: 100 mil a empresa aporta, 100 mil a EMBRAPII a porta e 100 mil é a nossa contrapartida que eu falei que não é financeiro. 100 mil vão ser de horas de trabalho mínimo do [Fulano] e das pessoas envolvidas, que são da equipe fixa. Esses 200 mil aqui, que são da empresa e da EMBRAPII, eles são utilizados para pagar as bolsas dos pesquisadores, para pagar as bolsas dos estagiários, para pagar os terceirizados, às vezes tem uma demanda específica que não têm aqui dentro e pode contratar de fora (...). Não fica nenhum centavo para o Polo" [E3]

Nesses fragmentos é possível observar que o Polo não se apresenta financeiramente sustentável, visto que não apresentam receitas que gerem fluxo de caixa a Instituição. Nesse 
sentido, necessita-se do subsídio econômico do IFMG para a manutenção das atividades rotineiras, como o pagamento dos colaboradores servidores do IFMG alocados no Polo de Inovação, compra de materiais de escritório, pagamento de auxiliares de limpeza e demais gastos. Além disso, a EMBRAPII auxilia financeiramente as atividades do Polo por meio do fomento exclusivo de projetos tecnológicos, como os pagamentos de bolsas para pesquisadores e estagiários, despesas com viagens, terceirização e outros investimentos.

Já a quarta categoria são os processos-chaves. Segundo Demil e Lecocq (2010) essa categoria inclui a cadeia de valor, em seus vários processos internos e sua rede de valor com os atores externos. Abaixo seguem os fragmentos ilustrativos extraídos com esse componente:

"Principal função, realmente, é desenvolver projetos de pesquisas, desenvolvimento e inovação e tem uma outra atividade importante no nosso modelo de negócio que a gente precisa aprimorar também, que é a formação de recursos humanos (...)” [E3].

"É, hoje como funciona no funil de vendas. Você tem uma fase de prospecção. No nosso caso ainda está bem ativa, porque a gente tem que pouco cliente de lead de vendas, pouca gente nos procurando. Mas já está começando a acontecer, a gente faz prospecções (...)” [E3].

"Bom acho que tem duas questões, três questões que eu vejo com importante. A primeira é fazer um endomarketing mais eficiente (...), segundo melhorar também o marketing para fora né, criar estratégias mais eficientes de se vender para as empresas (...) o terceiro acho que a gente tem que melhorar os processos internos, a gente tem que avançar muito nesse sentido." [E3]

Os trechos ilustrativos abordam cinco processos e atividades importantes para o Polo, são elas: desenvolvimento de projetos, capacitação dos pesquisadores, vendas de projetos, planejamento de marketing e processos internos. No que se refere ao desenvolvimento de projetos, capacitação dos pesquisadores e vendas de projetos, esses são considerados como processos críticos. Tais atividades são a base do negócio do Polo, no qual conseguem transformar a transferência de tecnologia em valor. Já as atividades de planejamento de marketing e processos internos foram colocados como ações que necessitam de melhorias. Cabe aqui ressaltar que, ao falar de vendas, E4 menciona o funil de vendas. Esse funil se baseia em três grandes atividades que são (i) prospecção: onde são feitos contatos com a empresa em potencial; (ii) negociação: articulação das negociações entre o Polo e as empresas potenciais e (iii) contratação: que é a realização da contratação da empresa visando o desenvolvimento do projeto. A Figura 01 apresenta o funil de vendas: 


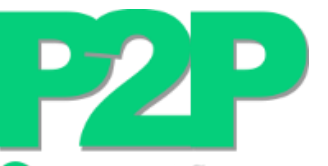

ARTIGO

INOVAÇÃO

Figura 01 - Funil de vendas

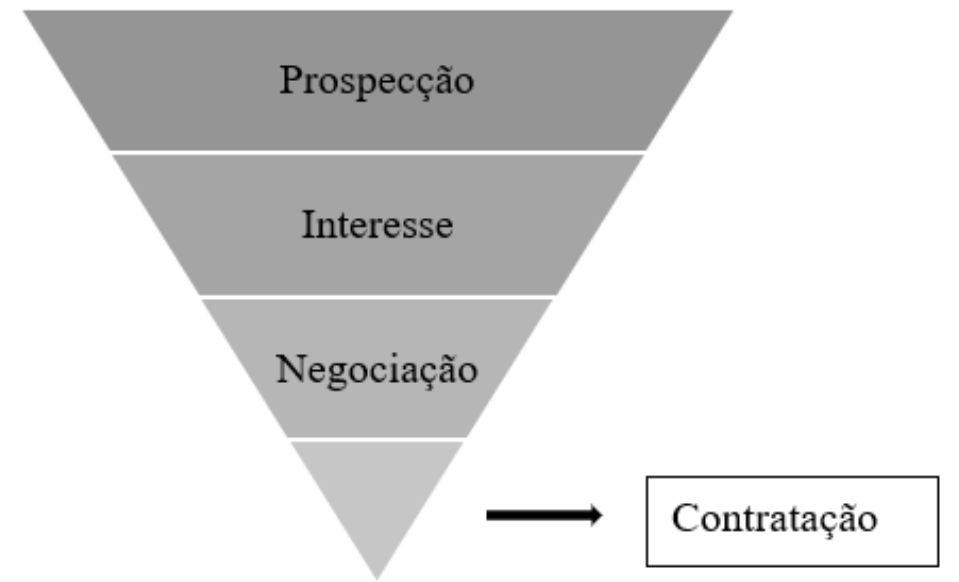

Fonte: elaborado pelos autores.

A quinta categoria são os recursos. Para Osterwalder e Pigneur (2011) os recursos representam o ponto mais importante exigido para executar o modelo de negócio. Segundo Antunes et al. (2019) os recursos podem ser tangíveis (humanos, físicos, financeiros) ou intangíveis (intelectuais, sociais). Logo, encontrou-se:

[Recursos Físicos] “A gente ocupa a três sala que é a nossa sala de direção, essa sala nossa de reunião e a sala de pesquisa na verdade são quatro e o laboratório da fiat de centro automotivos, então a gente ocupa essas salas do campus de formiga e a gente muitos muitas estruturas e Imobiliários e equipamentos foram adquiridos pelo polo que a gente recebeu, recursos do governo que chama TED que desde 2015 que essa TED foi liberada aqui para o polo a gente compro muitos equipamentos com recursos liberados pela TED que beneficiou também o campus, então a gente é beneficiados pelo campus e também foram beneficiados pelos recurso que a gente comprou. Equipamentos e mobiliários, entendeu?" [E2]

[Recursos Financeiros] "Todo o dinheiro administrado é depositado na conta da FURNABE, né o repasse que é feito da EMBRAPII, para a gente administrar, é depositado na conta da FURNABE, a empresa deposita na conta da FURNABE, então como que é feito, o pagamento é feito ao longo das macro entregas (...)" [E1]

[Recursos Sociais] “(...)A gente não tem contador, não temos advogados, assistente social não tem toda essa estrutura que o campus tem. Por isso que a gente fica meio dependente. A gente fica meio parasitando, mas pode ser que um dia, a gente se desvincule do Campus Formiga e vira autônomo e acho que isso seria o ideal (...)" [E3] 
[Recursos Humanos] “(...) Nós temos, hoje no Polo, Tem eu, o [FULANO] que está substituindo o [CICLANO 2], temporariamente, o [FULANO] é na parte de prospecção, (...) tem o [BELTRANO] nós temos a [FULANO 2], a [FULANO 2] é estagiária do Polo. $O$ [CICLANO 2] é responsável pelos laboratórios, (...) então montamos uma equipe por volta de seis pessoas, para fazer essa parte de gestão, essa é a equipe administrativa, que tá fixa, que vai fazer gestão e prestar conta (...)” [E1]

[Recursos Intelectuais] “(...) mas eu conto com todos os professores a partir do momento que a gente fecha um contrato, eu busco os talentos, né, (...) a cada contrato que eu fecho eu busco os professores onde estiverem, você tem aí, no último contrato eu tenho professor do Campus Ouro Branco, a maioria é do Campus Formiga, o contrato da [Empresa] o coordenador do contrato era do Campus de Arcos, então a equipe administrativa é fixa e a cada novo projeto eu busco aqueles professores que tem conhecimento para contribuir com o projeto e que queira né, que queira trabalhar, existe a compensação financeira, ele recebe uma bolsa, é uma bolsa de inovação ele recebe uma bolsa para trabalhar no projeto e os alunos também (...)”. [E1]

Segundo os relatos acima, observa-se que o Polo de Inovação atua com os recursos tangíveis e intangíveis. Como recursos tangíveis, encontra-se os físicos, traduzidos na infraestrutura, seja ela cedida ou própria; os humanos, com presença da diretoria geral, coordenadoria de prospecção de projetos, coordenação de portfólio (onde tem-se também a gestão de projetos) e a coordenação de pessoas, administrativa e financeira (POLO DE INOVAÇÃO DO IFMG, 2016); e financeiros, por meio do aporte da EMBRAPII à condução dos projetos. Já em relação aos recursos intangíveis as narrativas apontaram para os intelectuais, em que o recrutamento para os projetos se dá pelas competências dos docentes e discentes do IFMG; e o sociais que reflete na rede social utilizada para acessar outros recursos que não estão disponíveis ao Polo.

Por fim, a última categoria são os stakeholders. Em outras palavras envolve todos os atores que estão relacionados com a organização, abarcando desde a rede de fornecedores até clientes e parceiros de negócio (OSTERWALDER; PIGNEUR, 2011). Logo, E2 e E3 apontaram:

“(...) nós estamos dentro do IFMG não é de fora, mas a gente poderia considerar a reitoria um parceiro importante, o NIT que é o Núcleo de Inovação Tecnológica é um parceiro importante a gente está querendo estreitar as relações. A PRPPG que é Pro Reitoria de Pesquisa e Pós-Graduação, pode ser um parceiro importante também, a gente está precisando estreitar a relação com eles e as empresas obviamente." [E3]. 
“(...)Então, os professores e os alunos buscam colocar em prática os seus conhecimentos né, criar projetos e experimentar seus conhecimentos e fazer novas pesquisas (...)" [E2].

Como principais parceiros pode-se citar o próprio IFMG, com suas estâncias (Reitorias, Pró-reitorias, Núcelo de Inovação Tecnológica e demais), uma vez que o Polo se encontra dentro das dependências do Instituto. Desse modo, considera-se tal parceria como fundamental ao Polo, bem como a EMBRAPII para a execução dos projetos inovativos e tecnológicos. Numa outra possibilidade, destaca-se os docentes e discentes como possíveis mãos-de-obra qualificadas. Além disso, não menos que importante, destaca-se a própria sociedade, conforme E1 relata abaixo:

(...) Então o pessoal procura isso, pessoal tá vendo que em Formiga em vez de a gente trabalhar somente com comércio, somente com confecção a gente pode trazer algo que vai agregar no salário de verdade, né isso é importante para melhorar a renda da cidade, a medida que você trabalha com inovação tecnológica você tá trazendo a renda, as pessoas que estão trabalhando nisso vão ganhar dinheiro, então esse é um ponto importante né(...)[E1].

Por último, pode-se considerar que a sociedade civil, bem como seu representante, Governo Municipal, se beneficiam indiretamente do Polo, uma vez que ele traz desenvolvimento local.

\subsection{DISCUSSÕES SOBRE O MODELO DE NEGÓCIO DO POLO DE INOVAÇÃO DO IFMG}

Após a apresentação dos componentes do Modelo de Negócio do Polo de Inovação ser apresentado, se faz possível estabelecer a lógica do negócio dessa Instituição, bem como relacioná-la com a teoria.

Sendo assim, os resultados apontaram a emergência de três públicos, sendo eles a indústria, a academia e o governo. Esses alvos convergem com a literatura acerca dos objetivos dos SNI de fomentar o desenvolvimento tecnológico e inovativo, por meio do tripé governoacademia-empresa (BARBIERI, 1994; MCTIC, 2019). Além disso, esses públicos apresentam necessidades como capacitações técnicas, resolução de problemas, inovação tecnológica (setor industrial); relacionamento da teoria e prática (setor acadêmico) e difusão da inovação (setor governamental). Essas necessidades já foram apontadas por Barbieri (1994), Werneck (2006) e Souza et al. (2019). Logo, todas essas demandas são convertidas no valor do Polo, que é a transferência de tecnologia, que vem a ser entendida como repasse de conhecimentos 
específicos para um terceiro (BARBOSA JÚNIOR, 2013). Tais repasses de conhecimentos acontecem pela troca de informações científicas e técnicas, com especialização profissional em $\mathrm{P} \& \mathrm{D}$, uso de infraestrutura e outros projetos que envolvam a cooperação em pesquisa (ARVANITIS; SYDOW; WOERTER, 2008).

Para que o valor seja criado e entregue, três aspectos se fazem necessário. Primeiro, a estreita relação do Polo com seus parceiros IFMG, EMBRAPII e sociedade civil. No entanto, deve-se considerar as relações com o IFMG e com a EMBRAPII como parcerias críticas ao desenvolvimento do negócio do Polo de Inovação. Em outras palavras, pela falta de sustentabilidade financeira, o Polo se torna dependente dessas instituições, visto que elas influenciam os processos-chave do Polo. Como exemplo, compreende-se que sem a infraestrutura física e de pessoal do IFMG e sem o fomento aos projetos tecnológicos pela EMBRAPII, os projetos do Polo não conseguiriam se desenvolver, não ocorrendo, assim, os repasses de tecnologia. Dessa forma, ao se considerar a abordagem das alianças estratégicas, Narula e Hagedoorn (1999) apontam quatro níveis de parcerias entre organizações, é no quarto nível que se desenvolvem alianças estratégicas na área de $\mathrm{P} \& \mathrm{D}$, como os mecanismos mais eficientes de se desenvolver pesquisas em áreas de alta tecnologia. Portanto, pode-se considerar as relações do Polo com as duas Instituições o nível de alianças estratégicas.

O segundo fato importante para a transferência da tecnologia, são os recursos. Sem elas o valor não é concretizado. Desse modo, encontrou-se os recursos físicos, humanos, financeiros, intelectuais e sociais, sendo elas intimamente vinculados com os stakeholders. Dito de outra forma, é pelo fator social que todos os demais aspectos são obtidos. Segundo Nahapiet e Goshal (1998), ao abordarem a teoria do capital social, apontam que o propósito fundamental dessa teoria está associado com as análises do acesso aos recursos por meio dos laços da rede de contatos. Colaborando, Totterman e Sten (2005) apontam que os indivíduos/empresas buscam as redes visando confiar em terceiros para adquirir novos recursos necessários. Logo, percebese que no caso do Polo de Inovação, as relações sociais são o "pano de fundo" dos relacionamentos e das parcerias da Instituição, acarretando na obtenção dos demais recursos. Assim, aspectos como salas de reunião, escritórios, mobiliário, corpo de gestores, dinheiro e competências são obtidos devido a extensa relação social praticada institucionalmente.

O último fator para a criação do valor são os processos-chave. Assim, os resultados apontaram as atividades de desenvolvimento de projetos, capacitação dos pesquisadores e venda de projetos como os mais críticos, uma vez que são eles que transformam os recursos em valor. Isso ocorre a partir do momento que se compreende que esses três processos compõe o macroprocesso de transferência de tecnologia, contrariando o exporto por Hammer e Stanton 
(1995), de que os processos ainda continuam sendo fragmentados e isolados em diferentes áreas do negócio. Em outras palavras, a venda de projetos, por meio do funil de vendas, possibilita que o público alvo empresarial consiga enxergar a solução da sua necessidade. Logo, o desenvolvimento do projeto entre a academia e a empresa permite que o repasse de conhecimento seja realizado, num processo interativo e dinâmico valorizado pelo aprendizado baseado na prática, cumprindo, assim, a necessidade do agente governamental. Por fim, para que ocorra o projeto tecnológico e o aprendizado o corpo de pesquisadores (docentes e discentes) devem ter competências e capacidades para desenvolver a pesquisa aplicada.

Por fim, têm-se as receitas. No que se refere a esse elemento, ficou evidente que o Polo de Inovação não se apresenta financeiramente sustentável. Esse resultado se assemelha com outros trabalhos que utilizaram os modelos de negócio como nível de análise em outros ambientes de inovação, como incubadoras de empresas (ANTUNES; SIFUENTES; ALMEIDA, 2020; ANTUNES et al., 2019) e parques tecnológicos (CAVAZZA et al., 2018). Logo, pode-se considerar que a falta de recursos próprios dessas atmosferas devem ser enfoque de políticas públicas, sobretudo por meio da relação governamental abordado pelo SNI. Além disso, deve-se ressaltar que há a sustentabilidade econômica do Polo, que se traduz nas relações de fornecimentos de recursos físicos, gerenciais e financeiros dos parceiros.

Assim, compreende-se que a lógica do Polo de Inovação do IFMG é a criação e entrega de valor por meio da transferência tecnológica aos seus três principais públicos, industrial, acadêmicos e governamentais, de modo economicamente sustentável, embasando-se nos processos de desenvolvimento de projetos, capacitação técnica e vendas, que utilizam-se de recursos de infraestrutura, corpo gerencial, aporte financeiro, competências e relações sociais cedidos, principalmente, pelo IFMG e EMBRAPII.

\section{CONSIDERAÇÕES FINAIS}

O presente trabalho teve como objetivo analisar o modelo de negócios do Polo de Inovação do Instituto Federal de Minas Gerais (IFMG) localizado no Campus Formiga/MG. Como resultados encontrou-se três públicos-alvo compreendidos em industrial, governo e academia, em que cada um deles apresenta demandas específicas ao Polo. Tais demandas puderam ser convertidas na proposta de valor de transferência de tecnologia. Dessa forma, para que o valor ocorra, necessita-se das instituições parceiras como o IFMG e a EMBRAPII; de recursos físicos (infraestrutura), humana (gerencial), financeira, intelectual e social; e dos processos principais de desenvolvimento de projetos, capacitação de pessoal e vendas. Por fim, 
foi possível verificar que esse modelo de negócio se demonstra financeiramente deficitária, porém economicamente sustentável.

Como principais contribuições da pesquisa aponta-se a análise de Polos Tecnológicos, fator que tem apresentado escasso na literatura, descrevendo as particularidades desse tipo de negócio. Além disso, ressalta-se que essa pesquisa pode contribuir com novas políticas públicas a fim de melhorar a gestão dos Polos, especialmente na sua sustentabilidade financeira.

Como originalidade teórica-empírica conseguiu-se demonstrar, na prática, as relações da abordagem dos SNI. Já no viés da originalidade metodológica, tem-se o uso de componentes do modelo de negócio para compreender a atuação de um Polo de Inovação, ou seja, utiliza o modelo de negócio como nível de análise, conforme preconizado por Cavazza et al. (2018) e Antunes et al. (2019).

Em relação as limitações, expõe-se as dificuldades para a acessibilidade de outros atores envolvidos com o negócio do Polo de Inovação, como empresas e parceiros. Já como agenda de pesquisas futuras aponta-se a possibilidade de pesquisas quantitativas buscando ampliar e generalizar os resultados. Além de se argumentar sobre a reaplicação dessa pesquisa em outros ambientes de inovação. 


\section{REFERÊNCIAS}

ALMEIDA, A; FIGUEIREDO, A.; RUI SILVA, M. From concept to policy: building regional innovation systems in follower regions. European Planning Studies, v. 19, n.7, p. 1331-1356, 2011.

ANTUNES, L. G. R.; SIFUENTES, G. S; ALMEIDA, K. C. O Modelo de Negócio das Incubadoras de Empresas: Delineamento sob a ótica da Literatura Nacional e Internacional. Revista de Administração, Sociedade e Inovação (RASI), v. 6 n. 1, pp. 144-161, 2020.

ANTUNES, L. G. R.; SOUZA, T. A.; SILVA, J. P. N.; LOPES, G. C.; SUGANO, J. Y. Modelos de Negócio de Incubadoras de Empresas: Revisão de Escopo. Revista de Administração, Sociedade e Inovação (RASI), v. 5 n. 2, pp. 144-161, 2019.

ARVANITIS, S.; SYDOW, N.; WOERTER, M. Is there any Impact of University-Industry Knowledge Transfer on Innovation and Productivity? An Empirical Analysis Based on Swiss Firm Data. Review of Industrial Organization, Boston, v.32, n. 2, p.77-94, Mar. 2008.

BARBIERI, J. C. Pólos tecnológicos e de modernização: notas sobre a experiência brasileira. Revista de Administração de Empresas, v. 34, n.5, p. 21-31, 1994.

BARBOSA JÚNIOR, A. G. B. Serviços e Soluções Tecnológicas: manual básico do ciclo da inovação da UnB. Brasília: Centro de Apoio ao Desenvolvimento Tecnológico, 2013.

BARDIN, L. Análise de Conteúdo. São Paulo: Edições 70, 2016.

BOWMAN, C.; AMBROSINI, V. Value creation versus value capture: towards a coherent definition of value in strategy. British Journal of Management, v. 11, n. 1, p. 1-15, 2000.

BRASIL. Lei N. 13.243, de 11 de janeiro de 2016. Dispõe sobre estímulos ao desenvolvimento científico, à pesquisa, à capacitação científica e tecnológica e à inovação. Brasília: 11 janeiro 2016.

CARVALHO, L. C.; MACHADO, D. D. N. Ambiente de Inovação: estudo comparativo entre três unidades de uma organização do setor metal-mecânico. REGEPE-Revista de

Empreendedorismo e Gestão de Pequenas Empresas, v. 2, n.1, p. 47-76, 2013.

CASADESUS-MASANELL, R; RICART, J. E. From strategy to business models and onto tactics. Long Range Planning, v. 43, n. 2, p. 195-215, 2010.

CAVAZZA, B. H.; SOUZA, T. A.; ANTUNES, L. G. R; MINEIRO, A. A. C.; ZAMBALDE, A. L. Modelos de Negócios como Unidade de Análise: Um estudo comparativo. In: Atena Editora. (Org.). A Gestão Estratégica na Administração. 1ed. Ponta Grossa: Atena, 3, p. 188-207, 2018.

CHISTENSEN, C. M. The Innovator's Dilemma. Harvard: Harvard Business School Press, 1997.

DAMANPOUR, F. Organizational innovation: A meta-analysis of effects of determinants and moderators. Academy of Management Journal, v.34, n. 3, p. 555-590, 1991. 
DEMIL, B.; LECOCQ, X. Business model evolution: in search of dynamic consistency. Long Range Planning, v. 43, n. 2, p. 227-246, 2010.

FIORE, A; GRISORIO, M. J; PROTA, F. Regional Innovation Systems: Which role for public policies and innovation agencies? Some insights from the experience of an Italian region. European Planning Studies, v. 19, n. 8, p. 1399-1422, 2011.

FREEMAN, C.; SOETE, L. A economia da inovação industrial. Tradução: André Luiz Sica de Campos e Janaina Oliveira Pamplona da Costa. Campinas, SP: Editora da UNICAMP, 2008.

GIL, A. C. Métodos e técnicas de pesquisa social. 6. ed. São Paulo: Atlas SA, 2008.

GODOY, A. S. Refletindo sobre critérios de qualidade da pesquisa qualitativa. Gestão.org, v. 3, n. 2, p. 80-89, 2005.

HAMMER, M.; STANTON, S. A. A revolução da reengenharia: um guia prático. Trad. Bazán Tecnologia. Rio de Janeiro: Campus. 1995.

HIJJAR, M. F. Segmentação de mercado para diferenciação dos serviços logísticos. Logística empresarial: a perspectiva brasileira. São Paulo: Atlas, 2000.

MACEDO, M. M. L.; DUARTE, M. A. T. Caracterização do Ambiente de Inovação de uma Empresa de Informações para Decisão de Negócios. Revista Gestão Industrial, v. 8, p. 188203, 2013.

MACIEL, M. L. Inovação e conhecimento. In: SOBRAL, F. et al. (Orgs.). A alavanca de Arquimedes: ciência e tecnologia na virada do século. Brasília: Paralelo 15, 1997.

MARIGHETTI, A; SPOSITO, E. S. A formação dos polos tecnológicos e seu papel no processo de desenvolvimento territorial no município de São Carlos/SP. Geografia em Atos (Online), v. 1, n. 9, 2009.

MARTINS, Y. C. P; WANDER, A. E. Demandas Tecnológicas para o Polo de Inovação Tecnológica em Soja do Instituto Federal Goiano. Revista GEINTEC, v. 8, n. 4, p.46704683, 2018.

MCTI - MINISTÉRIO DA CIÊNCIA, TECNOLOGIA, INOVAÇÕES E COMUNICAÇÕES. Polos Tecnológicos. Brasília, 2019. Disponível em www.mctic.gov.br. Acesso em: 10 dez. 2020.

MEDEIROS, J. A.; MATTEDI, A. P; MARCHI, M. M. Pólos tecnológicos e núcleos de inovação: lições do caso brasileiro. Revista de Administração, v. 25, n.4, p. 3-12, 1990.

MEDEIROS, J. A.; MEDEIROS, L. A; MARTINS, T; PERILO, S. Pólos, parques e incubadoras: em busca da modernização e competitividade. Brasília: CNPq, 1992.

MEYER-KRAHMER, F; SCHMOCH, U. Science-based technologies: university-industry interactions in four fields. Research Policy, v. 27, n. 8, pp.835-851, 1998.

NAHAPIET, J; GHOSHAL, S. Social capital, intellectual capital, and the organizational advantage. Academy of Management Review, v. 23, n. 2, p. 242-266, 1998. 
NARULA, R.; HAGEDOORN, J. Innovating through strategic alliances: moving towards international partnerships and contractual agreements. Technovation, 19, p. 283-294, 1999.

OECD - ORGANIZATION FOR ECONOMIC CO-OPERATION AND DEVELOPMENT. Manual de Oslo - Diretrizes para coleta e interpretação de dados sobre inovação. tradução FINEP, Brasília: OECD, 2006.

OSTERWALDER, A. The Business Model Ontology-a proposition in a design science approach. 2004. 173p. Dissertação, Universidade de Lausanne, Suiça, 2004.

OSTERWALDER, A; PIGNEUR, Y. Business model generation: inovação em modelos de negócios. Alta Books Editora. 2011.

PAVITT, K. The social shaping of the national science base. Research Policy, v. 27, n. 8, pp.793-805, 1998.

POLO DE INOVAÇÃO DO IFMG. Institucional, 2016. Disponível em https://www.polodeinovacao.ifmg.edu.br. Acesso em: 10 fev. 2017.

RAMOS, P; RAMOS, M. M; BUSNELLO, S. J. Manual prático de metodologia da pesquisa: artigo, resenha, projeto, TCC, monografia, dissertação e tese. Blumenau: Acadêmica. 2005.

RICHARDSON, R. J. Pesquisa social: métodos e técnicas. São Paulo: Atlas. 1989.

SANTOS, A. B. A; FAZION, C. B.; MEROE, G. P. S. Inovação: um estudo sobre a evolução do conceito de Schumpeter. Caderno de Administração. Revista da Faculdade de Administração da FEA, v. 5, n.1, 2011.

SCHUMPETER, J. A. A Teoria do Desenvolvimento Econômico: uma investigação sobre lucros, capital, crédito, juro e o ciclo econômico. 3. ed. São Paulo: Abril Cultural, 1982.

SOUZA, T. A; ANTUNES, L. G. R.; AZEVEDO, A D. S; ANGÉLICO, G. O; ZAMBALDE, A. L. Innovative performace of Brazilian public higher educational institutions: Analysis of the remuneration of research groups and companies. Innovation \& Management Review, v. 16, n. 4, pp.323-343, 2019.

TIMMERS, P. Business models for electronic markets. Electronic Markets, v. 8, n. 2, p. 3-8. 1998.

TORKOMIAN, A. L. V.. Fundação ParqTec: o órgão gestor do Pólo de Alta Tecnologia de São Carlos. Ciência da Informação, v. 23, n. 2, 1994.

TÖTTERMAN, H.; STEN, J. Start-ups: Business incubation and social capital. International Small Business Journal, v. 23, n. 5, p. 487-511, 2005.

TRIPPL, M. Developing cross-border regional innovation systems: Key factors and challenges. Tijdschriftvoor Economischeen Social e Geografie, v. 101, n. 2, p. 150-160, 2010 .

WERNECK, V. R. Sobre o processo de construção do conhecimento: o papel do ensino e da pesquisa. Ensaio: avaliação e políticas públicas em educação, v. 14, n. 51, p. 173-196, 2006. 
- INOVAÇÃO

ZALTMAN, G; DUNCAN, R; HOLBEK, J. Inovações e organizações. Nova Jersey: John Wiley \& Sons. 1973. 